\title{
Highly efficient mesenchymal stem cell proliferation on poly- $\varepsilon$-caprolactone nanofibers with embedded magnetic nanoparticles
}

This article was published in the following Dove Press journal:

International Journal of Nanomedicine

7 December 2015

Number of times this article has been viewed

\author{
Jana Daňková ${ }^{1,2}$ \\ Matej Buzgo 1,3,4 \\ Jana Vejpravová5 \\ Simona Kubíčková ${ }^{5}$ \\ Věra Sovková1,2 \\ Lucie Vysloužilová ${ }^{4,6}$ \\ Alice Mantlíková ${ }^{5}$ \\ Alois Nečas ${ }^{7}$ \\ Evžen Amler ${ }^{1-3}$
}

'Laboratory of Tissue Engineering, Institute of Experimental Medicine, Academy of Sciences of the Czech Republic, Prague, Czech Republic; ${ }^{2}$ Institute of Biophysics, Second Faculty of Medicine, Charles University in Prague, Prague, Czech Republic; ${ }^{3}$ Faculty of Biomedical Engineering, Czech Technical University in Prague, Kladno, Czech Republic; ${ }^{4}$ University Center for Energy Efficient Buildings, Czech Technical University in Prague, Bustehrad, Czech Republic; ${ }^{5}$ Department of Magnetic Nanosystems, Institute of Physics, Academy of Sciences of the Czech Republic, Prague, Czech Republic; ${ }^{6}$ Department of Nonwoven Textiles, Faculty of Textile Engineering, Technical University of Liberec, Liberec, Czech Republic; ${ }^{7}$ Faculty of Veterinary Medicine, University of Veterinary and Pharmaceutical Sciences Brno, Brno, Czech Republic

Correspondence: Jana Daňková Laboratory of Tissue Engineering, Institute of Experimental Medicine, Academy of Sciences of the Czech Republic, 1083 Vídeňská, Prague 142 20, Czech Republic

Tel +420 296442387

Fax +420296442387

Email jana_dankova@labdemo.cz
Abstract: In this study, we have developed a combined approach to accelerate the proliferation of mesenchymal stem cells (MSCs) in vitro, using a new nanofibrous scaffold made by needleless electrospinning from a mixture of poly-e-caprolactone and magnetic particles. The biological characteristics of porcine MSCs were investigated while cultured in vitro on composite scaffold enriched with magnetic nanoparticles. Our data indicate that due to the synergic effect of the poly- $\varepsilon$-caprolactone nanofibers and magnetic particles, cellular adhesion and proliferation of MSCs is enhanced and osteogenic differentiation is supported. The cellular and physical attributes make this new scaffold very promising for the acceleration of efficient MSC proliferation and regeneration of hard tissues.

Keywords: magnetic particles, mesenchymal stem cells, nanofibers, tissue engineering

\section{Introduction}

There is an increasing amount of data reporting on the bioeffects of magnetic particles and magnetic fields, which has led us to carry out a study to understand the way in which they influence living organisms. Magnetic particles are widely used in medicine, and have attracted attention especially due to their potential as contrast agents for magnetic resonance imaging (MRI) and as heating mediators for cancer therapy (hyperthermia).

Although magnetic particles are extensively used in medicine, their influence on cells and living organisms remains unclear. Various methods and applications with magnetic particles are used for gene and drug delivery, including magnetofection, ${ }^{1,2}$ magnetite cationic liposomes cell labeling, ${ }^{3}$ and antibody-conjugated magnetoliposome cell labeling, ${ }^{4}$ but the effects of magnetic particles on cellular processes have not been sufficiently investigated. There is an evidence that magnetic labeling of mesenchymal stem cells (MSCs) increased their rate of proliferation approximately five times, ${ }^{4}$ but the influence of embedded magnetic particles in nanofibrous material on MSC proliferation and differentiation has not been fully examined in the past.

Magnetic nanoparticles (MNPs) usually consist of magnetic elements such as iron, nickel, or cobalt, and they may vary in composition depending on the specific application. For biomedical applications, characteristics such as nontoxicity and biocompatibility are essential. Materials such as cobalt and nickel have excellent magnetic properties in bulk; however, they can be toxic to the human body. ${ }^{5}$ By contrast, materials such as magnetite $\left(\mathrm{Fe}_{3} \mathrm{O}_{4}\right)$ and maghemite $\left(\gamma-\mathrm{Fe}_{2} \mathrm{O}_{3}\right)$ have high oxidative stability, and they are currently the only accepted nontoxic magnetic nanomaterials for medical applications. ${ }^{6,7}$ While used in regenerative medicine, particle size is a target of focus with respect to tissue distribution. Particles smaller than $50 \mathrm{~nm}$ evade opsonization and can circulate for a longer period, 
whereas larger particles are rapidly cleared from the blood by sinusoidal Kupffer cells in the liver, therefore have limited uptake in lymph and bone tissues. ${ }^{8}$

MSCs are nonhematopoietic cells with the ability to differentiate into cells of mesodermal origin tissues such as osteoblasts, chondrocytes, adipocytes, and tenocytes. ${ }^{9-11}$ However, there is evidence of their capacity to differentiate into cells from all three germ layers. ${ }^{12}$ The ease with which they can be manipulated and isolated from an autologous source makes these cells attractive for tissue regeneration applications. However, the number of MSCs isolated from bone marrow is just a small fraction of the cells (between $0.001 \%$ and $0.01 \%$ ), varying according to the isolation technique that is used. ${ }^{13}$ Because the number of cells after isolation is not sufficient for therapeutic applications, ex vivo expansion is a necessary step for clinical applications of MSCs.

Electrospun nanofibers have attracted much attention in recent years. The main advantage of nanofibers arises from their morphology mimicking the extracellular matrix. Submicron fibers for a mesh with huge porosity and pore interconnection facilitate efficient nutrient and waste product transfer. Additionally, the huge surface-to-volume ratio enables efficient binding of proteins and supports cell adhesion. ${ }^{14}$ Electrospinning is a simple technique for producing nanofibrous layers. ${ }^{15}$ It is based on the interaction of a charged polymeric liquid with a strong electric field. As of now, more than 200 polymers have been successfully electrospun. ${ }^{14}$ Biocompatible and biodegradable polymers are materials of special importance. Biocompatibility is a critical factor when creating tissue-engineering materials. Poly- $\varepsilon$-caprolactone (PCL) is a biocompatible, bioresorbable polyester approved by the US Food and Drug Administration and widely used in tissue engineering applications. ${ }^{16}$ It has a favorable surface chemistry for cellular adhesion and has been shown to promote the attachment and proliferation of MSCs. ${ }^{17}$ In contrary to other polyester, such as polylactic acid, polyglycolic acid and their copolymers, the PCL exhibits longer stability, and the degradation products do not acidify the surrounding environment. $^{18}$

In the present study, we have employed needleless electrospinning to prepare a PCL/MNP composite material. Additionally, we have examined the interaction of MSCs with a PCL nanofiber scaffold including MNPs (PCL-MNPs). No external magnetic field was applied.

\section{Materials and methods}

\section{Scaffold preparation}

Nanofiber scaffolds were prepared by electrospinning. Electrospinning was performed with a mixture of $24 \mathrm{wt} \%$
PCL with a molecular weight of 45,000 Da (Sigma-Aldrich, St Louis, MO, USA) using a chloroform:ethanol dissolving system in a ratio of 9:1. Twenty-four grams of PCL were mixed with $90 \mathrm{~mL}$ of chloroform and $10 \mathrm{~mL}$ of ethanol. A sample with magnetic particles was prepared by dispersing $10 \mathrm{mg} / \mathrm{mL}$ of MNPs (Sigma-Aldrich) with a manufacturer specified size of 50-100 nm. The particles were mixed with PCL solution under stirring to obtain homogenous dispersion. The control PCL samples were prepared without adding nanoparticles. The electrospinning electrode was based on a PTFE (polytetrafluoroethylene) needleless electrode connected to a high-voltage source by a copper wire. Multispin STS 13-01 (Student Science, Horni Podluzi, Czech Republic) was utilized as an electrospinning platform. The electrode had a rod-like morphology and was connected to the positive power supply. A metal plate collector connected to the negative power supply covered with spun bond textile was utilized for collecting the prepared fibers in the form of a nonwoven mesh. The temperature during all electrospinning process was maintained at $24^{\circ} \mathrm{C} \pm 2^{\circ} \mathrm{C}$ and $60 \% \pm 2 \%$ humidity.

\section{Characterization of the magnetic particles and the scaffold}

The MNPs and the as-prepared scaffolds were characterized by high-resolution scanning electron microscopy (HR-SEM) and magnetization measurements. Nanoparticle powder X-ray diffraction and Mössbauer spectroscopy of the bare MNPs were also performed. The HR-SEM images were recorded on MIRA 3 (Tescan, Brno, Czech Republic) with an acceleration voltage of $15 \mathrm{keV}$ and a working distance of approximately $3 \mathrm{~mm}$.

The morphology of the nanofibrous mesh was examined using a Tescan VEGA3 scanning electron microscope (Tescan). The samples were coated with a gold layer using a sputter coater (Quorum Technologies, Guelph, ON, Canada) and were visualized at $10 \mathrm{kV}$ accelerating voltage. The mean fiber diameter was measured using ImageJ software (National Institutes of Health, Maryland, USA).

The temperature dependence of the zero-field-cooled (ZFC) magnetization and the field-cooled (FC) magnetization in an external magnetic field of $10 \mathrm{mT}$, and magnetization isotherms at selected temperatures were measured with a SQUID magnetometer MPMS 7XL (Quantum Design, San Diego, CA, USA). The powder diffractograms were recorded in Bragg-Brentano geometry using an X'Pert Pro MPD diffractometer (Bruker, Billerica, MA, USA) equipped with $\mathrm{CuK} \alpha$ radiation; the data were further analyzed using the Rietveld refinement method implemented in FullProf software (Institut Laue-Langevin, Grenoble, France) considering the instrumental function of the diffractometer in the profile 
analysis. The room temperature Mössbauer spectra were measured using a Mössbauer spectrometer (WissEl Wissenschaftliche Elektronik GmbH, Starnberg, Germany). The spectra were refined using the NORMOS software (WissEl Wissenschaftliche Elektronik GmbH, Starnberg, Germany).

\section{MSC isolation and cultivation}

MSCs were obtained from the os ilium bone marrow of miniature pigs (Institute of Animal Physiology and Genetics of the Academy of Sciences of the Czech Republic, Libechov, Czech Republic). Bone marrow blood was aspirated into $10 \mathrm{~mL}$ syringes with $5 \mathrm{~mL}$ Dulbecco's phosphate-buffered saline (PBS), 2\% fetal bovine serum (PAA Laboratories, Pasching, Austria) and $25 \mathrm{IU}$ heparin/mL connected with a bioptic needle $(15 \mathrm{G} / 70 \mathrm{~mm})$. Isolation on MSCs was performed under sterile conditions. Five milliliters of gelofusine was added to the bone marrow blood (approximately $20 \mathrm{~mL}$ ), which was placed into $50 \mathrm{~mL}$ centrifuge tubes. After 30 minutes of incubation, the blood was centrifuged at $400 \times g$ for 15 minutes. Then, the layer of mononuclear cells was removed and seeded into a culture flask and cultured at $37^{\circ} \mathrm{C}$ in a humidified atmosphere with $5 \% \mathrm{CO}_{2}$. $\alpha$-Minimum Essential Medium with Earle's Salt and L-glutamine (SigmaAldrich) supplemented with $10 \%$ fetal bovine serum and penicillin/streptomycin $(100 \mathrm{IU} / \mathrm{mL}$ and $100 \mu \mathrm{g} / \mathrm{mL}$, respectively; Sigma-Aldrich) was used as a culture medium.

\section{Cell seeding}

Round-shaped scaffolds (6 $\mathrm{mm}$ in diameter) were sterilized by ethylene oxide at $37^{\circ} \mathrm{C}$. Subsequently, the cells were trypsinized by trypsin-ethylenediaminetetraacetic acid (Sigma-Aldrich) and seeded on scaffolds at a density of $62.5 \times 10^{3} / \mathrm{cm}^{2}$ in a 96 -well plate. The MSCs were cultivated in $250 \mu \mathrm{L}$ of medium (of the type mentioned above) per well. The cultivating medium was changed every 3 days. All methods used for analysis were performed on days 1, 7, and 21 after seeding. Tests for cell metabolic activity, proliferation and also alkaline phosphatase (ALP) activity were always performed on the same sample.

\section{Cell metabolic activity analysis}

3-(4,5-Dimethylthiazol-2-yl)-5-(3-carboxymethoxyphenyl)2-(4-sulfophenyl)-2H-tetrazolium (MTS) assay (CellTiter $96^{\circledR}$ AQueous One Solution Cell Proliferation Assay; Promega Corporation, Fitchburg, WI, USA) was used to measure the metabolic activity of the cells. Twenty microliters of MTS was added to $100 \mu \mathrm{L}$ of fresh cultivating medium per well. The plates were incubated for 4 hours at $37^{\circ} \mathrm{C}$ and $5 \% \mathrm{CO}_{2}$. Then, the results were measured by spectrophotometry in $100 \mu \mathrm{L}$ per well, using a multimode microplate reader (Synergy HT; BioTek, Winooski, VT, USA) at $490 \mathrm{~nm}$, with a reference at $690 \mathrm{~nm}$.

\section{Cell proliferation analysis}

A PicoGreen assay kit (Quant-iT ${ }^{\text {TM }}$ PicoGreen $^{\circledR}$ dsDNA Assay Kit, Thermo Fisher Scientific, Waltham, MA, USA) was used to determine the cell proliferation. First, $500 \mu \mathrm{L}$ of cell lysis solution (radioimmunoprecipitation assay lysis buffer [150 mM NaCl, $10 \mathrm{mM}$ Tris, $0.1 \% \mathrm{w} / \mathrm{v}$ sodium dodecyl sulfate, $0.1 \% \mathrm{v} / \mathrm{v}$ Triton $\mathrm{X}-100,24 \mathrm{mM}$ sodium deoxycholate, $50 \mathrm{mM}$ ethylenediaminetetraacetic acid]) was added to each well with a scaffold. Subsequently, the samples were processed through three freeze/thaw cycles, in which the scaffold samples were deep frozen and then thawed at room temperature. Between cycles, the samples were roughly vortexed. The samples were then stored at $-70^{\circ} \mathrm{C}$ until analysis. The amount of DNA was determined according to instructions by mixing $200 \mu \mathrm{L}$ of PicoGreen reagent and $10 \mu \mathrm{L}$ of sample. The samples were loaded in triplicates, and the fluorescence intensity was measured on a multiplate fluorescence reader (Synergy HT, $\lambda_{\mathrm{ex}}=480-500 \mathrm{~nm}$, $\lambda_{\mathrm{em}}=520-540 \mathrm{~nm}$; BioTek). A calibration curve based on standards was created to evaluate the amount of DNA.

\section{ALP activity assay}

The ALP activity of the cells was measured using $p$-nitrophenyl phosphate (pNPP) as a phosphatase substrate which turns yellow $\left(\lambda_{\max }=405 \mathrm{~nm}\right.$ ) when dephosphorylated by ALP ( $p$-Nitrophenyl Phosphate Liquid Substrate System; Sigma-Aldrich). The activity of this enzyme was monitored on days 1,7 , and 21 . First, the medium was removed from the wells and $100 \mu \mathrm{L}$ of pNPP reagent was added to each well with a scaffold sample. Then, the plates were incubated for 15 minutes at $37^{\circ} \mathrm{C}$ and $5 \% \mathrm{CO}_{2}$. After that, the pNPP reagent was transferred into new wells and the reaction was stopped by adding $1 \mathrm{M} \mathrm{NaOH}$, and was read at $405 \mathrm{~nm}$ using a microplate reader.

\section{Confocal microscopy of MSCs}

Confocal microscopy was used on days 1,7 , and 21 to visualize the cells on the scaffolds. The cells on the scaffolds were fixed by $3.7 \%$ formaldehyde for 30 minutes, rinsed three times with PBS and incubated with Tetramethylrhodamine B isothiocyanate Phalloidin Conjugate (Sigma-Aldrich, diluted $100 \times$ ) for 1 hour at room temperature. The cell nucleus was stained with Hoechst 33342 (Thermo Fisher Scientific, diluted 1:25). Both were diluted in PBS. After incubation, the scaffolds were rinsed three times with PBS and scanned 
the same day. Phalloidin binds with high affinity to the polymerized form of actin, and enables us to visualize the cell cytoskeleton, while Hoechst is a DNA intercalating dye used for nucleus staining. A Zeiss LSM 5 DUO confocal microscope was used for scanning $\left(\lambda_{\mathrm{ex}}=560 \mathrm{~nm}\right.$ and $\lambda_{\mathrm{em}}>575 \mathrm{~nm}$ for rhodamine, $\lambda_{\mathrm{ex}}=405 \mathrm{~nm}$ and $\lambda_{\mathrm{em}}=420-480 \mathrm{~nm}$ for Hoechst; Zeiss, Oberkochen, Germany).

\section{Statistical analysis}

The results were evaluated statistically using one-way analysis of variance and the Student-Newman-Keuls method. SigmaStat software (Systat Software Inc., Chicago,
IL, USA) was used for this purpose. The data are presented as the mean \pm standard deviation. Average values were determined from at least three independently prepared samples.

\section{Results}

\section{Structural and magnetic characterization}

First, the MNPs and the as-prepared scaffolds with MNPs were analyzed by HR-SEM. Typical HR-SEM images are shown in Figure 1. The MNPs appeared as spherical objects of size between 50 and $100 \mathrm{~nm}$, forming irregular agglomerates (Figure 1A). This is typical for powder samples obtained
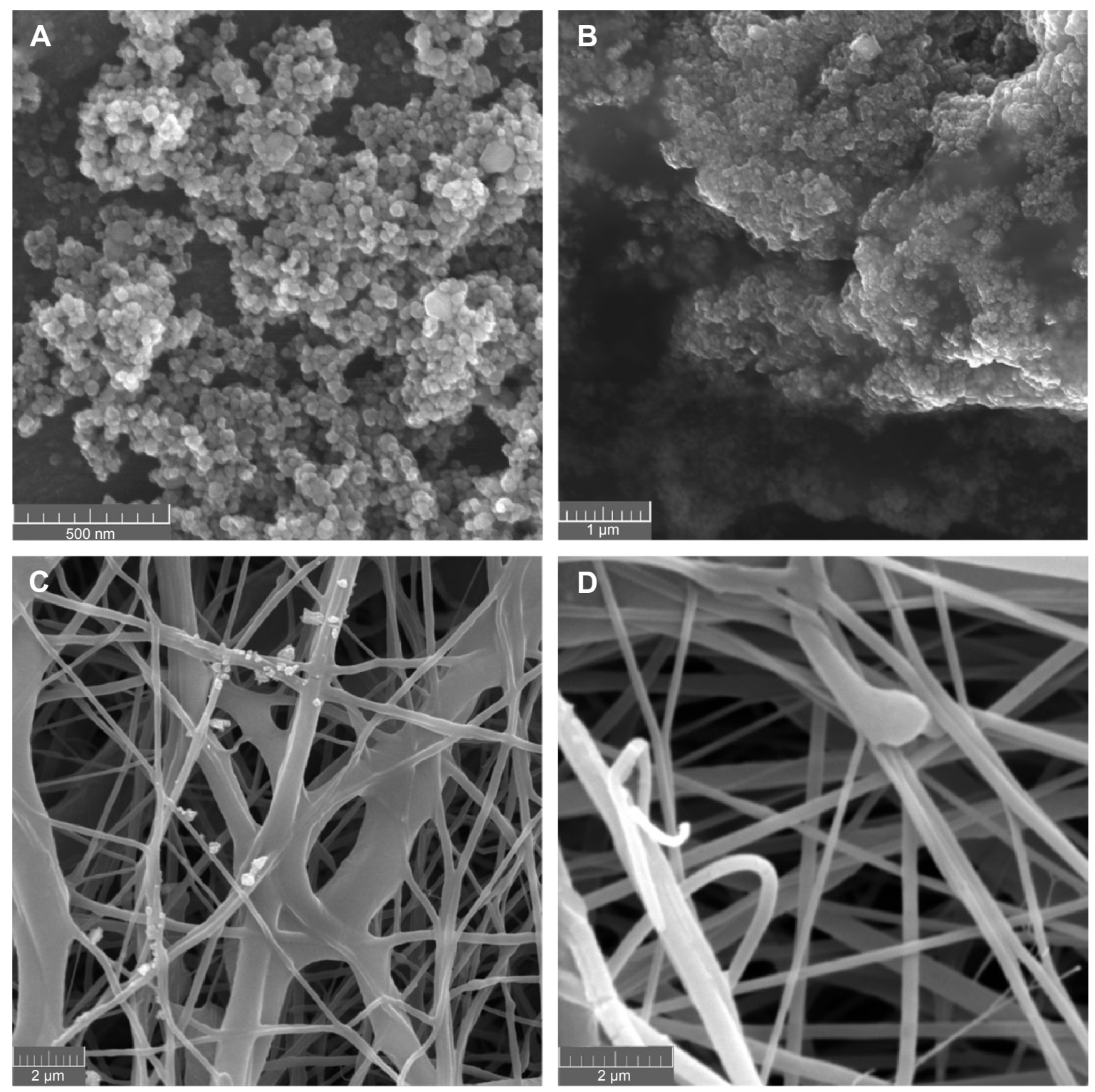

Figure I (A and B) High-resolution scanning electron microscopy of the bare MNPs and the thawed scaffold with MNPs; (C and D) scanning electron microscopy of the nanofiber scaffold with and without MNPs.

Notes: (A) MNPs (magnification $\times 65,000$ ); (B) thawed PCL-MNPs (magnification $\times 20,000$ ); (C) PCL-MNPs (magnification $\times 7,500$ ); (D) PCL scaffold (magnification $\times 12,000$ ). Abbreviations: MNPs, magnetic nanoparticles; PCL-MNPs, poly- $\varepsilon$-caprolactone scaffold with magnetic nanoparticles; PCL, poly- $\varepsilon$-caprolactone. 
by the coprecipitation method and subsequent drying. The nanofibers with magnetic particles embedded in PCL showed a nano/microfibrous morphology (Figure 1C). The mesh consisted of a microfibrous fraction with fiber diameter $1,138 \pm 474 \mathrm{~nm}$ and a dominant nanofibrous fraction with mean fiber diameter $216 \pm 91 \mathrm{~nm}$. This type of morphology is typical for PCL electrospun from a chloroform:ethanol solvent system. Figure $1 \mathrm{C}$ shows partial distribution of MNPs on the nanofiber surface. Imaging of the melted PCL nanofibers with magnetic particles showed that the MNPs embedded in the scaffold form a relatively homogeneous composite (Figure 1B). These results indicate that a significant fraction of the MNPs is located inside the fibers. The PCL sample without MNPs exhibited a similar morphology (Figure 1D). The predominant nanofibrous fraction of PCL nanofibers without MNPs had a mean fiber diameter of $301 \pm 103 \mathrm{~nm}$

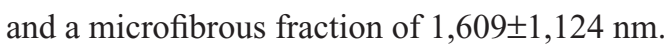

The MNPs were characterized by powder X-ray diffraction and Mössbauer spectroscopy to prove chemical composition and crystal structure of the MNPs; the results together with the fit of the experimental data are shown in Figure 2. The diffraction pattern (Figure 2A) corresponded to the spinel structure, and the obtained lattice parameter, $\mathrm{a}=8.3631 \pm 0.0005 \AA$, suggested that MNPs were formed from maghemite $\left(\gamma-\mathrm{Fe}_{2} \mathrm{O}_{3}\right)$ as a result of topotactic oxidation of magnetite. The particle size (diameter) by means of the coherently diffracting domain was determined as $23 \pm 2 \mathrm{~nm}$. In comparison with the particle size observed by HR-SEM, the value for the diameter - reduced by approximately a half obtained by X-ray diffraction suggests either a considerable amount of noncrystalline volume or particle aggregation, as is typical for nanoparticles prepared by coprecipitation. The analysis of the Mössbauer spectrum consists of two sextets

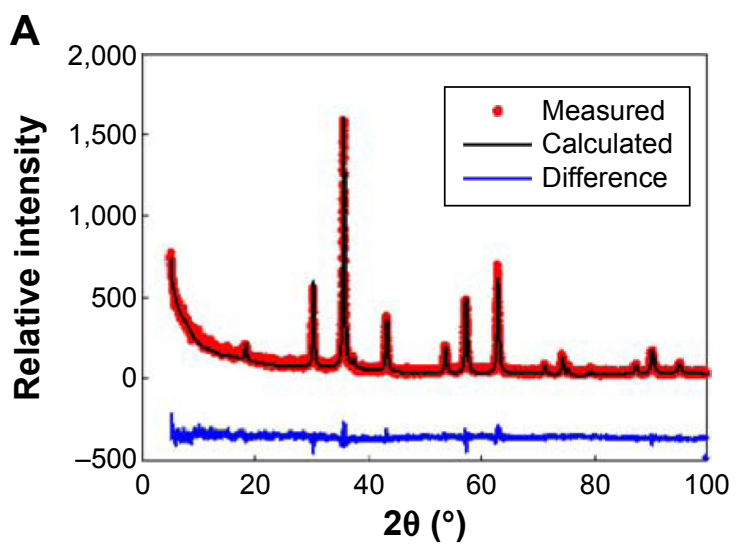

corresponding to the tetrahedral and octahedral coordination of $\mathrm{Fe}^{3+}$ (Figure 2B). The content of the $\mathrm{Fe}^{2+}$ was found to be negligible, so the sample contained mainly maghemite phase. This is coherent with the results of the XRD and magnetization measurements. The presence of the sextets suggests that the MNPs are in the blocked state; the superparamagnetic blocking temperature is, therefore, at least $100 \mathrm{~K}$ above room temperature.

The magnetic properties of the MNPs and the MNPs enriched scaffolds were finally examined by magnetization measurements. The magnetization isotherms $(\mathrm{M}(\mathrm{H}))$, shown in Figure 3A, reveal a typical trend for iron oxide nanoparticles above $20 \mathrm{~nm}$ in size, as demonstrated by the rapid approach to saturation and a net paramagnetic-like contribution (a linear component to the $\mathrm{M}(\mathrm{H})$, which does not saturate), which is originated by the presence of a magnetically disordered volume of MNPs (a magnetically dead shell). The saturation magnetization values of the bare MNPs, $\mathrm{M}_{\mathrm{s}}$, are $85.7 \pm 0.5 \mathrm{Am}^{2} / \mathrm{kg}$ and $76.4 \pm 0.5 \mathrm{Am}^{2} / \mathrm{kg}$ at $10 \mathrm{~K}$ and $300 \mathrm{~K}$, respectively, are only slightly lower than for the bulk maghemite $\left(80 \mathrm{Am}^{2} / \mathrm{kg}\right.$ at $\left.300 \mathrm{~K}\right)$. The values for the scaffold were determined as follows: $6.8 \pm 0.3 \mathrm{Am}^{2}$ and $6.1 \pm 0.3 \mathrm{Am}^{2}$ at $10 \mathrm{~K}$ and $300 \mathrm{~K}$, respectively. Considering the values obtained for $\mathrm{M}_{\mathrm{s}}$, we may estimate the content of MNPs in the composite as $7.9 \pm 0.1 \mathrm{wt} \%$. The coercivity varies only moderately when embedding the MNPs; details of the low-field part of the hysteresis loops for the bare MNPs and the scaffold are shown in Figure 4. While the room temperature values are identical within the experimental error $(0.004 \pm 0.001 \mathrm{~T})$, the $10 \mathrm{~K}$ value of the composite is $0.028 \pm 0.002 \mathrm{~T}$ in comparison to $0.016 \pm 0.003 \mathrm{~T}$. This effect can be explained by a change of the surface anisotropy contribution of the MNPs due to the fabrication process. The ZFC and FC dependencies of

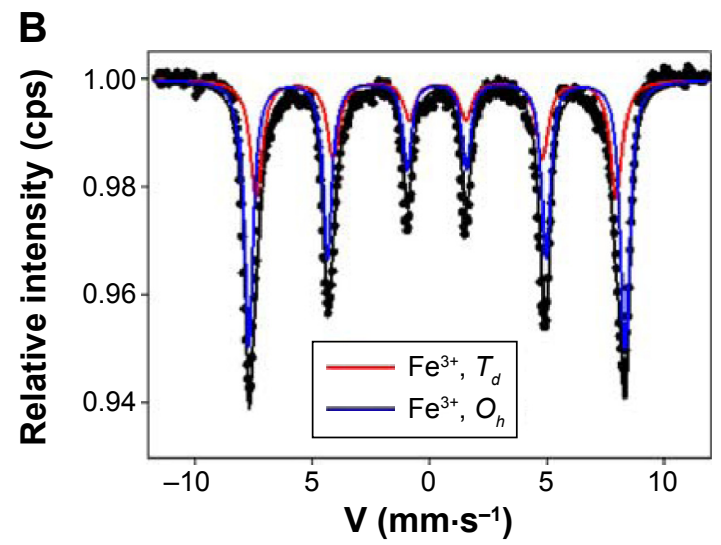

Figure 2 (A and B) Powder X-ray diffractogram and Mössbauer spectrum of the MNPs, both measured at room temperature. Notes: (A) X-ray diffractogram of the MNPs; (B) Mössbauer spectrum of the MNPs. Abbreviation: MNPs, magnetic nanoparticles. 
A

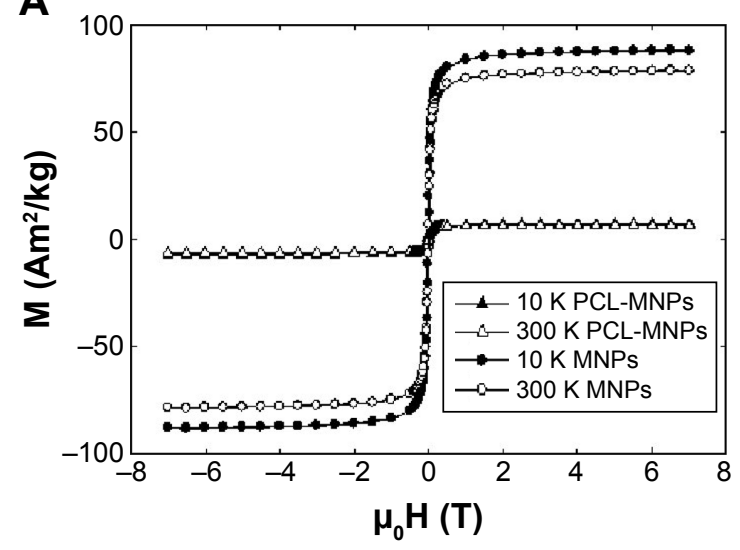

B

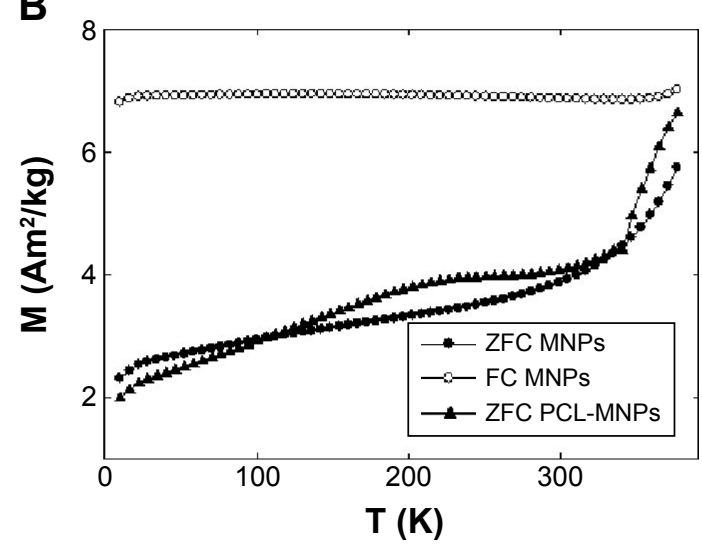

Figure 3 ( $\mathbf{A}$ and $\mathbf{B}$ ) Comparison of the magnetic characterization of the bare MNPs and the scaffold with MNPs.

Notes: (A) Magnetization isotherms recorded at low temperature and at room temperature, respectively; (B) the temperature dependence of the ZFC and FC magnetization for bare MNPs and the ZFC curve for the scaffold PCL-MNPs. The kink at approximately $350 \mathrm{~K}$ on the ZFC curve of the scaffold sample corresponds to melting of the fibers.

Abbreviations: MNPs, magnetic nanoparticles; PCL-MNPs, poly- $\varepsilon$-caprolactone scaffold with magnetic nanoparticles; ZFC, zero-field-cooled; FC, field-cooled.

magnetization, shown in Figure 3B, follow a trend typical for iron oxide nanoparticles above $20 \mathrm{~nm}$ in size. In accordance with the Mössbauer results, the MNPs are in the blocked state at room temperature (confirmed by the net hysteresis observed on $\mathrm{M}(\mathrm{H})$ at $300 \mathrm{~K}$ ). The $\mathrm{ZFC}$ curve shows a kink at approximately $50 \mathrm{~K}$, which can be attributed to the incoherent electron tunneling of the electrons of the remnant $\mathrm{Fe}^{2+}$ ions in the magnetite phase, typical for highly oxidized magnetite. ${ }^{19}$ The ZFC and FC curves do not coincide up to the highest temperature available for measurement (390 K), so the blocking temperature is even higher. The ZFC curve of the composite more or less follows the trend of the bare particles; the sudden upturn at approximately $350 \mathrm{~K}$ suggests melting of the polymer, which has a melting temperature approximately $60^{\circ} \mathrm{C}$. The magnetic measurements suggest the negligible influence of the preparation process on the magnetic performance of the MNPs used here.

\section{Metabolic activity of the cells}

The MSCs' metabolic activity, proliferation, and ALP activity were monitored for a period of 21 days to test the biocompatibility of the scaffolds and the influence of the MNPs in the PCL on the cells.

First, the metabolic activity of the cells seeded on the scaffolds was determined by means of an MTS assay (Figure 5). The cells were cultivated with an MTS substrate. Subsequently, the absorbance was measured on an enzymelinked immunosorbent assay reader at $490 \mathrm{~nm}$. The cell metabolic activity increased throughout the experimental period on both types of scaffold. However, the viability of
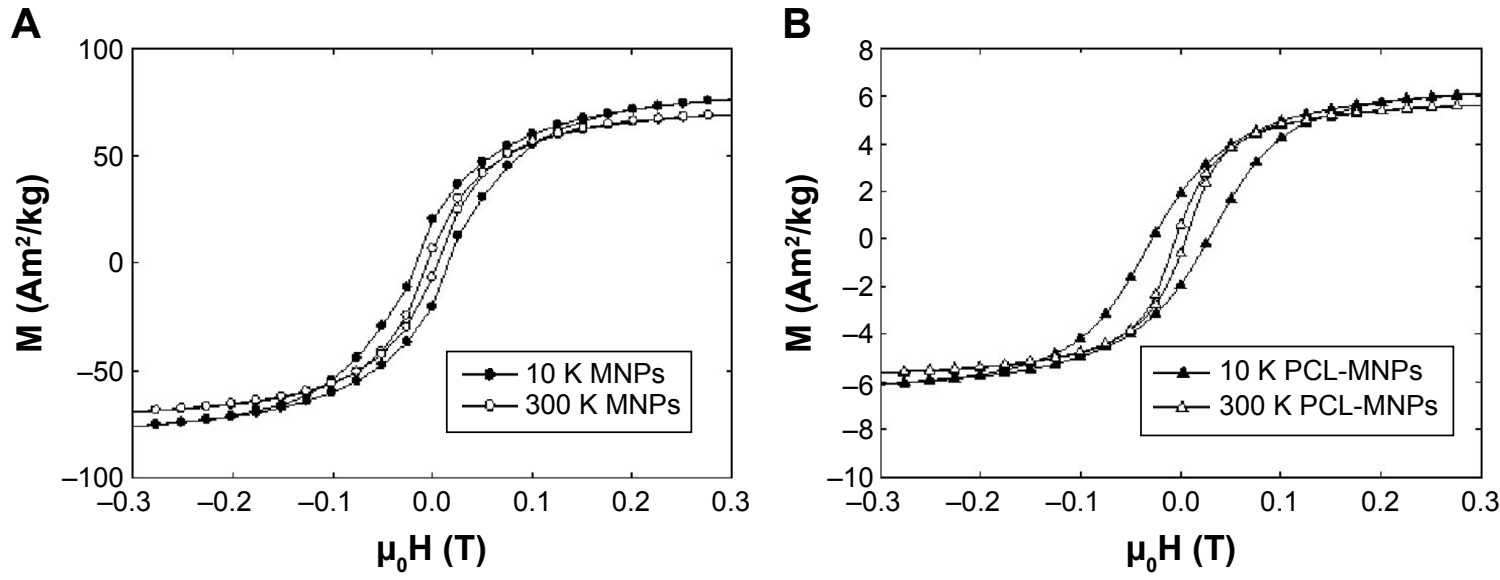

Figure 4 (A and B) Detail of the hysteresis loops recorded at low temperature and at room temperature, respectively.

Notes: (A) Hysteresis loop for the bare MNPs; (B) hysteresis loop for the PCL-MNPs. A moderate increase in the coercivity of the scaffold samples can be observed at I0 K. Abbreviations: MNPs, magnetic nanoparticles; PCL-MNPs, poly- $\varepsilon$-caprolactone scaffold with magnetic nanoparticles. 


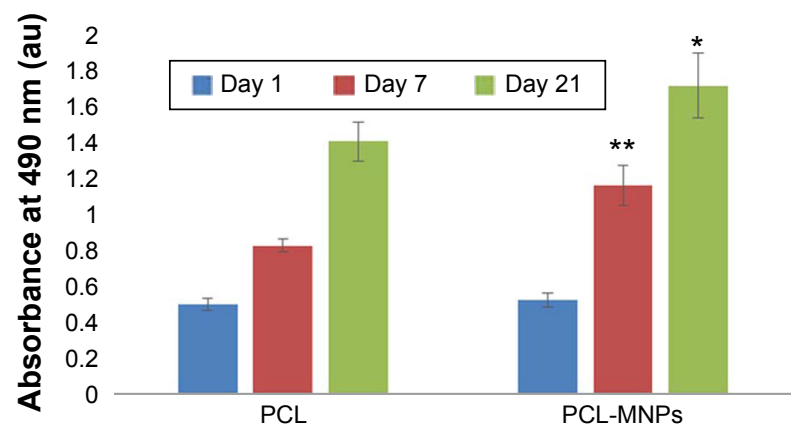

Figure $\mathbf{5}$ Metabolic activity of the MSCs measured by MTS assay.

Notes: Statistical analysis: $* P<0.05 ; * * P<0.001$.

Abbreviations: MSCs, mesenchymal stem cells; MTS, 3-(4,5-dimethylthiazol-2yl)-5-(3-carboxymethoxyphenyl)-2-(4-sulfophenyl)-2H-tetrazolium; PCL, poly- $\varepsilon$ caprolactone scaffold; PCL-MNPs, poly- $\varepsilon$-caprolactone scaffold with magnetic nanoparticles.

the cells cultivated on PCL-MNPs was significantly higher on days 7 and 21 than for the cells seeded on the scaffolds made from PCL.

\section{Cell proliferation}

In order to compare the cell proliferation in samples with and without MNPs, a PicoGreen assay was performed to estimate the DNA values in the scaffolds (Figure 6). Clearly, cultivation on scaffolds containing MNPs resulted in a significantly higher amount of DNA on the 1st day of cultivation. This can be explained by better cell adhesion. Static cell proliferation on the PCL scaffold was observed over a period of 7 days. After that, cell proliferation decreased between days 7 and 21 $(P<0.05)$. However, the cell number seeded on PCL-MNPs increased significantly from day 1 to day 21 . This conclusion is also supported by confocal microscopy observations (Figure 7).

\section{ALP activity}

To test the effect on MSC differentiation of magnetic particles incorporated into PCL nanofibers, the ALP activity

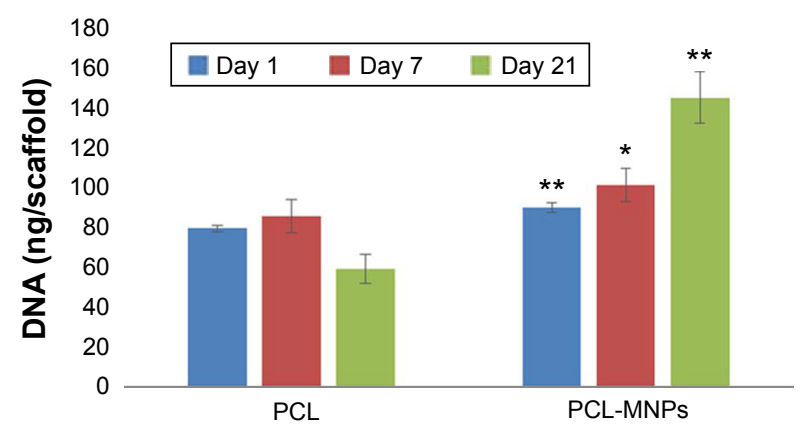

Figure 6 Proliferation of the MSCs determined using PicoGreen assay. Notes: Statistical analysis: $* P<0.05 ; * * P<0.001$.

Abbreviations: MSCs, mesenchymal stem cells; PCL, poly- $\varepsilon$-caprolactone scaffold; PCL-MNPs, poly- $\varepsilon$-caprolactone scaffold with magnetic nanoparticles. was measured using an ALP assay (Figure 8). Surprisingly, the ALP activity was significantly higher in cells seeded on the PCL scaffolds on day 1 . After that, a significant increase in ALP activity was observed for MSCs cultivated on the PCL-MNPs scaffolds on days 7 and 21.

\section{Confocal microscopy}

The cell spreading and cell morphology were evaluated by confocal microscopy on days 1, 7, and 21 (Figure 7). Phalloidin-rhodamine fluorescent stain was utilized for actin microfilament visualization. Cell nuclei were visualized with Hoechst 33342 stain. On the 1st day, the cells on the PCL scaffolds were homogeneously distributed and had a nonspread morphology. By contrast, the cells on the PCL-MNPs scaffolds were well spread, indicating better initial cell adhesion. This morphology correlates with the Picogreen assay results, where the cell number on the 1st day was significantly higher. On day 7 , the cells on the PCL scaffold were isolated in small colonies and were sparsely spread. The cells on the PCL-MNPs scaffold were localized in larger colonies, and had a well-spread morphology. The number of cells increased gradually during the experimental period; however, the cell layer was fully confluent on the PCL-MNPs scaffolds. On day 21, the cells on the PCL were localized in huge colonies and showed a well spread morphology, indicating good biocompatibility of PCL. However, the cell layer was not fully confluent. These results correlate with our results from viability and proliferation assays.

\section{Discussion}

The influence of the magnetic materials on biological subjects is rather complicated but heavily discussed. Biocompatibility is one of the key factors while fabricating tissue-engineering materials. In this study, we used PCL as a slowly degradable, biocompatible polymer to create nanofibers with incorporated magnetic particles. PCL with a molecular weight of $45 \mathrm{kDa}$ was utilized for the development of nanofibers. This molecular weight is ideal for electrospinning from chloroform:ethanol solvent system. We have recently demonstrated biocompatibility of the system with fibroblasts ${ }^{20}$ and MSCs. ${ }^{21}$ In addition, the PCL with this molecular weight enables degradation in vivo in the time frame of bone regeneration. ${ }^{22}$ It was indicated that the higher amount of MNPs is used to fabricate the scaffold, the more significant stimulation of cell adhesion, proliferation, and differentiation is observed. ${ }^{23,24}$ Simultaneously, the degree of saturation magnetization is increasing with increasing concentration of $\gamma-\mathrm{Fe}_{2} \mathrm{O}_{3}$ in the composite from $0 \mathrm{wt} \%$ to $10 \mathrm{wt} \%{ }^{25}$ Bare iron oxide nanoparticles can be toxic in a 

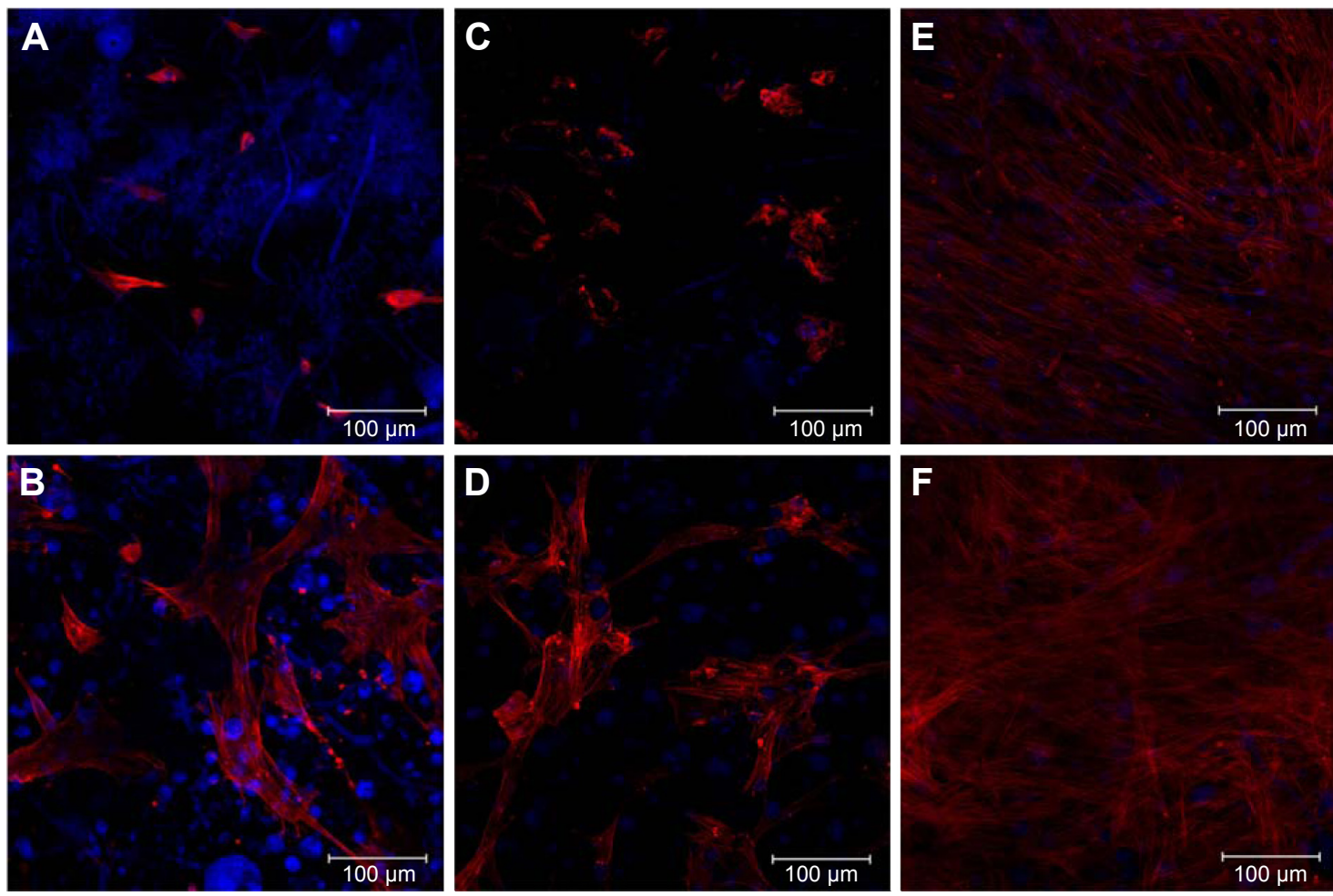

Figure 7 (A-F) Fluorescent staining of the MSCs cultured on PCL and PCL-MNPs, respectively. Phalloidin-rhodamine was used to stain cytoplasm (red), DNA was stained by Hoechst 33342 (blue).

Notes: (A) MSCs on PCL scaffold on day I; (B) MSCs on PCL-MNPs scaffold on day I; (C) MSCs on PCL scaffold on day 7; (D) MSCs on PCL-MNPs scaffold on day 7; (E) MSCs on PCL scaffold on day 21 ; (F) MSCs on PCL-MNPs scaffold on day 21.

Abbreviations: MSCs, mesenchymal stem cells; PCL, poly- $\varepsilon$-caprolactone scaffold; PCL-MNPs, poly- $\varepsilon$-caprolactone scaffold with magnetic nanoparticles.

dose-dependent manner in vitro. ${ }^{26}$ The viability of cells was decreased up to $5 \%$ if the concentration of particles was 100 $\mathrm{mg} / \mathrm{mL}$. Taken all these facts into consideration, the concentration corresponding to approximately $10 \mathrm{wt} \% \mathrm{MNPs}$ in the final composite was used.

We focused here on the influence of embedded MNPs in PCL scaffold prepared by needleless electrospinning on MSCs in vitro. Here, an MTS assay was performed to verify the biocompatibility of our composite material. The cells showed

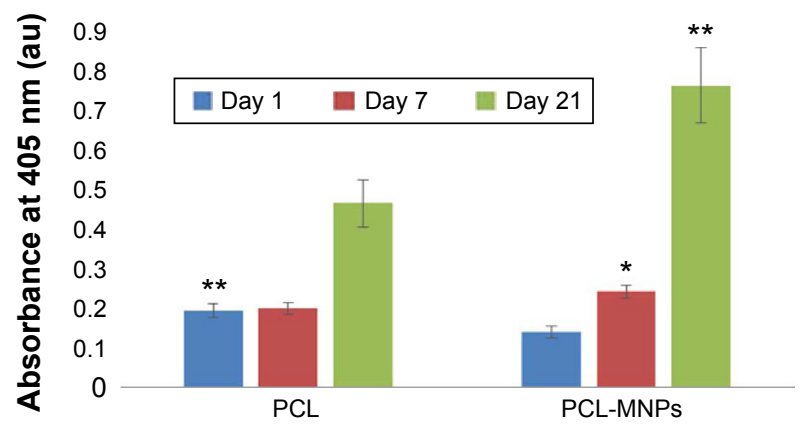

Figure 8 Alkaline phosphatase activity of the MSCs.

Notes: Statistical analysis: $* P<0.05 ; * * P<0.00$ I

Abbreviations: MSCs, mesenchymal stem cells; PCL, poly- $\varepsilon$-caprolactone scaffold; PCL-MNPs, poly- $\varepsilon$-caprolactone scaffold with magnetic nanoparticles. significantly better viability on days 7 and 21 when seeded on the PCL-MNPs scaffold than on PCL alone. There have been some studies showing increased viability of cells if they are cultivated on composite material with MNPs, ${ }^{27,28}$ but there has been no evidence of such an increase in cellular viability without using external field until now. Cells were seeded in the same numbers in our experiment, and the biggest difference in cell viability was clearly documented on day $7(P<0.001)$. On day 21 , the difference in cell viability between the groups was not so large, but it is still significant $(P<0.05)$.

In the second part of the study, we focused on cell proliferation, where a significant difference in the amount of DNA between the groups was monitored. The PCL-MNPs group showed faster proliferation of cells as early as on day 1 of the experiment. The proliferation increased gradually in the case of PCL-MNPs, while on day 21, there was the biggest difference between the PCL-MNPs group and the PCL group. This was clearly confirmed by confocal microscopy, which showed that there was better cell adhesion and accelerated proliferation. These results accord with other studies using nanofiber scaffolds made from polymeric material with MNPs, where good cell adhesion and proliferation was observed. ${ }^{29-32}$ 
In the last test, we demonstrated that the PCL-MNPS scaffolds did not restrict MSCs differentiation when the ALP activity increased significantly in cells cultivated on the PCLMNPs. On day 1, there was bigger ALP activity in the PCL group, but on day 7 the situation had rapidly changed in favor of the PLC-MNPs. The ALP activity continued to increase gradually until day 21 . Other studies have also reported the beneficial effect of magnetic particles in polymeric scaffold for differentiation of preosteoblasts ${ }^{27,28}$ as well as support and enhancing of osteogenic differentiation of MSCs. ${ }^{31,33-35}$ Studies showing that there is no significant change in the cell multidifferentiation capacity of bone marrow stromal cells if they are magnetically labeled can also indicate that magnetic particles may support differentiation of cells. ${ }^{36,37}$

PCL nanofiber meshes are widely used for tissue engineering applications, due to their ability to mimic the extracellular matrix and promote cellular adhesion, growth, and proliferation. Nanofibers enriched by MNPs have shown even better properties for MSCs and for their proliferation. Although the effects of magnetic particles on living organisms are still not fully understood, many new composite biomaterials comprising magnetic particles or coatings have been developed. In bone tissue engineering, there has been a big accrual of new materials promoting osteoblast proliferation. Titanium with hydrothermally treated nanocrystalline hydroxyapatites/magnetically treated carbon nanotubes has been designed to enhance osteoblast adhesion and promote osseointegration. ${ }^{34}$ Novel magnetic nanohydroxyapatite (m-nHAP) coated $\gamma-\mathrm{Fe}_{2} \mathrm{O}_{3}$ /polyvinyl alcohol composite hydrogels have been designed, and the adhesion density and proliferation of the osteoblasts have been promoted significantly, while increasing the m-nHAP content in the composite hydrogels. ${ }^{31}$ In the next study, magnetite $\left(\mathrm{Fe}_{3} \mathrm{O}_{4}\right)$ nanoparticles were synthesized and coated with hydroxyapatite. ${ }^{35}$ Long-term osteoblast experiments demonstrated greater ALP activity, total protein synthesis, collagen synthesis, and calcium deposition in the presence of hydroxyapatite-coated iron oxide nanoparticles. A magnetic biodegradable $\mathrm{Fe}_{3} \mathrm{O}_{4} /$ chitosan (CS)/polyvinyl alcohol nanofibrous membrane has also been developed as a material with potential use in bone regeneration. ${ }^{29}$ Poly(lactic-co-glycolic acid) and hydrophobic superparamagnetic MNPs were combined together to construct composite scaffolds with excellent biocompatibility, promoting cell proliferation and differentiation of MC3T3-E1 cells. ${ }^{32}$

At this point, cellular and tissue reactions as were reported in our study as well as in other studies, should be reasoned. As described in many articles, magnetic materials positively influence cellular adhesion, proliferation, and differentiation of cells. ${ }^{23,24,27-35}$ The reason can lie in the magnetic characteristics of material. Magnetic scaffolds can generate a magnetic field to the surroundings, which consequently alters microenvironment conditions of cells. If each MNP is considered as a single magnetic domain on nanoscale level, it might affect ion channels and influence cellular processes. ${ }^{38}$ Moreover, cells are known to respond to mechanical stimuli, which initiate signaling pathways influencing cell membrane dynamics. The signals can be transduced via direct activation of mechanosensitive ion channels or through deformation of cell membranes. MNPs functionalized with specific peptides or antibodies to attach particles to ion channels or surface receptors have been shown to cause membrane polarization, receptor activation, and activation of downstream signals in human MSCs due to membrane deformation caused by exposure to magnetic field. ${ }^{39,40}$ If particles which are not navigated by antibody to specific channels or receptors can cause mechanical stimulation of cells remains unclear, however, bone tissue is believed to recognize the mechanoelectrical conversion leading to increased cellular proliferation and expression levels of multiple bone differentiation markers. ${ }^{41}$ Because the incorporation of MNPs into scaffold leads to increase the rate of bone cell proliferation and differentiation, we can suppose that MNPs work in a similar way. As a further possible explanation, superparamagnetic iron oxide nanoparticles were discovered to promote human MSC growth and accelerate the cell cycle due to the ability to decrease intracellular $\mathrm{H}_{2} \mathrm{O}_{2}$ and change the expression of cell cycle regulators through free iron $(\mathrm{Fe})$ released from lysosomal degradation. ${ }^{42}$ To investigate the real inductor of observed effects, more information has to be found out. The fact is that the characteristics of cells cultured on magnetic scaffold were significantly improved in terms of cell adhesion, spreading, proliferation, and differentiation. Magnetic particles play a key role in providing such properties to the final composite; however, the mechanism how the scaffold helps to regenerate and repair tissue may be multifactorial.

\section{Conclusion}

In this study, we have developed a combined methodological approach for accelerating MSCs proliferation in vitro using a nanofibrous composite scaffold made from PCL with embedded MNPs by needleless electrospinning. Our results showed great biocompatibility, ability to promote cellular adhesion, accelerate MSCs' proliferation, and support osteogenic differentiation. Due to these features, this scaffold could be considered as a promising tool for accelerated expansion of MSCs in vitro and an ideal candidate especially for bone tissue engineering applications. 


\section{Acknowledgments}

This work has been supported by the Academy of Sciences of the Czech Republic (Institutional Research Concept RVO 68378041), the Grant Agency of Charles University (grant numbers 424213, 1246314, 270513, 1262414, 1228214, 545313, 648112), the Internal Grant Agency of the Ministry of Health of the Czech Republic (NT12156), the Czech Science Foundation Grant No 15-15697S, the University Centre for Energy Efficient Buildings (UCEEB) support IPv6, and the Ministry of Education, Youth, and Sports of the Czech Republic (Research Programs NPU I:LO1508 and NPU I:LO1309). Sample characterization was supported by the MULTIFUN project (European Commission $7 \mathrm{FP}$, No 262943 and MSMT No 7E12057). Magnetic measurements were performed at MLTL (see http://mltl.eu), which is supported within the Czech Research Infrastructures program (project no LM2011025).

\section{Disclosure}

The authors report no conflicts of interest in this work.

\section{References}

1. Scherer F, Anton M, Schillinger U, et al. Magnetofection: enhancing and targeting gene delivery by magnetic force in vitro and in vivo. Gene Ther. 2002;9(2):102-109.

2. Mykhaylyk O, Antequera YS, Vlaskou D, Plank C. Generation of magnetic nonviral gene transfer agents and magnetofection in vitro. Nat Protoc. 2007;2(10):2391-2411.

3. Shinkai M, Yanase M, Honda H, Wakabayashi T, Yoshida J, Kobayashi T. Intracellular hyperthermia for cancer using magnetite cationic liposomes: in vitro study. Jpn J Cancer Res. 1996;87(11):1179-1183.

4. Ito A, Hibino E, Shimizu K, et al. Magnetic force-based mesenchymal stem cell expansion using antibody-conjugated magnetoliposomes. J Biomed Mater Res B Appl Biomater. 2005;75(2):320-327.

5. Vadala ML, Zalich MA, Fulks DB, St Pierre TG, Dailey JP, Riffle JS. Cobalt-silica magnetic nanoparticles with functional surfaces. J Magn Magn Mater. 2005;293(1):162-170.

6. Müller R, Steinmetz H, Hiergeist R, Gawalek W. Magnetic particles for medical applications by glass crystallisation. J Magn Magn Mater. 2004;272-276(Pt 2):1539-1541.

7. Häfeli UO, Pauer GJ. In vitro and in vivo toxicity of magnetic microspheres. J Magn Magn Mater. 1999;194(1-3):76-82.

8. Barry SE. Challenges in the development of magnetic particles for therapeutic applications. Int J Hyperthermia. 2008;24(6):451-466.

9. Deng ZL, Sharff KA, Tang N, et al. Regulation of osteogenic differentiation during skeletal development. Front Biosci. 2008;13:2001-2021.

10. Friedenstein AJ, Petrakova KV, Kurolesova AI, Frolova GP. Heterotopic of bone marrow. Analysis of precursor cells for osteogenic and hematopoietic tissues. Transplantation. 1968;6(2):230-247.

11. Luu HH, Song WX, Luo X, et al. Distinct roles of bone morphogenetic proteins in osteogenic differentiation of mesenchymal stem cells. J Orthop Res. 2007;25(5):665-677.

12. D'Ippolito G, Diabira S, Howard GA, Roos BA, Schiller PC. Low oxygen tension inhibits osteogenic differentiation and enhances stemness of human MIAMI cells. Bone. 2006;39(3):513-522.

13. Pittenger MF, Mackay AM, Beck SC, et al. Multilineage potential of adult human mesenchymal stem cells. Science. 1999;284(5411):143-147.

14. Sill TJ, von Recum HA. Electrospinning: applications in drug delivery and tissue engineering. Biomaterials. 2008;29(13):1989-2006.
15. Lukáš D, Sarkar A, Martinová L, et al. Physical principles of electrospinning. Text Prog. 2009;41(2):59-140.

16. Puppi D, Chiellini F, Piras AM, Chiellini E. Polymeric materials for bone and cartilage repair. Prog Polym Sci. 2010;35(4):403-440.

17. Rampichova M, Chvojka J, Buzgo M, et al. Elastic three-dimensional poly (epsilon-caprolactone) nanofibre scaffold enhances migration, proliferation and osteogenic differentiation of mesenchymal stem cells. Cell Prolif. 2013;46(1):23-37.

18. Woodruff MA, Hutmacher DW. The return of a forgotten polymer Polycaprolactone in the 21st century. Prog Polym Sci. 2010;35(10): 1217-1256.

19. Roca AG, Niznansky D, Poltierova-Vejpravova J, et al. Magnetite nanoparticles with no surface spin canting. J Appl Phys. 2009;105(11):7.

20. Plencner M, East B, Tonar Z, et al. Abdominal closure reinforcement by using polypropylene mesh functionalized with poly-epsilon-caprolactone nanofibers and growth factors for prevention of incisional hernia formation. Int J Nanomed. 2014;9:3263-3277.

21. Mickova A, Buzgo M, Benada O, et al. Core/shell nanofibers with embedded liposomes as a drug delivery system. Biomacromolecules. 2012;13(4):952-962.

22. Prosecká E, Rampichová M, Litvinec A, et al. Collagen/hydroxyapatite scaffold enriched with polycaprolactone nanofibers, thrombocyte-rich solution and mesenchymal stem cells promotes regeneration in large bone defect in vivo. J Biomed Mater Res A. 2015;103(2):671-682.

23. Zeng XB, Hu H, Xie LQ, et al. Magnetic responsive hydroxyapatite composite scaffolds construction for bone defect reparation. Int J Nanomed. 2012;7:3365-3378.

24. Singh RK, Patel KD, Lee JH, et al. Potential of magnetic nanofiber scaffolds with mechanical and biological properties applicable for bone regeneration. PLoS One. 2014;9(4):e91584

25. Agarwal K, Prasad M, Sharma RB, Setua DK. Studies on microstructural and thermophysical properties of polymer nanocomposite based on polyphenylene oxide and ferrimagnetic iron oxide. Polym Test. 2011; 30(1):155-160.

26. Sadeghi L, Tanwir F, Yousefi Babadi V. In vitro toxicity of iron oxide nanoparticle: oxidative damages on Hep G2 cells. Exp Toxicol Pathol. 2015;67(2):197-203.

27. Kannarkat JT, Battogtokh J, Philip J, Wilson OC, Mehl PM. Embedding of magnetic nanoparticles in polycaprolactone nanofiber scaffolds to facilitate bone healing and regeneration. J Appl Phys. 2010;107(9):09B307.

28. Cai Q, Shi Y, Shan D, et al. Osteogenic differentiation of MC3T3-E1 cells on poly(l-lactide)/Fe3O4 nanofibers with static magnetic field exposure. Mater Sci Eng C Mater Biol Appl. 2015;55:166-173.

29. Wei Y, Zhang X, Song Y, et al. Magnetic biodegradable Fe3O4/CS/ PVA nanofibrous membranes for bone regeneration. Biomed Mater. 2011;6(5):055008.

30. Hu H, Jiang W, Lan F, et al. Synergic effect of magnetic nanoparticles on the electrospun aligned superparamagnetic nanofibers as a potential tissue engineering scaffold. RSC Adv. 2013;3(3):879-886.

31. Hou R, Zhang G, Du G, et al. Magnetic nanohydroxyapatite/PVA composite hydrogels for promoted osteoblast adhesion and proliferation. Colloids Surf B Biointerfaces. 2013;103:318-325.

32. Lai K, Jiang W, Tang JZ, et al. Superparamagnetic nano-composite scaffolds for promoting bone cell proliferation and defect reparation without a magnetic field. RSC Adv. 2012;2(33):13007-13017.

33. Gloria A, Russo T, D'Amora U, etal. Magnetic poly(epsilon-caprolactone)/ iron-doped hydroxyapatite nanocomposite substrates for advanced bone tissue engineering. J R Soc Interface. 2013;10(80):20120833.

34. Wang M, Castro NJ, Li J, Keidar M, Zhang LG. Greater osteoblast and mesenchymal stem cell adhesion and proliferation on titanium with hydrothermally treated nanocrystalline hydroxyapatite/magnetically treated carbon nanotubes. J Nanosci Nanotechnol. 2012;12(10):7692-7702.

35. Tran N, Webster TJ. Increased osteoblast functions in the presence of hydroxyapatite-coated iron oxide nanoparticles. Acta Biomater. 2011; 7(3):1298-1306.

36. Riegler J, Liew A, Hynes SO, et al. Superparamagnetic iron oxide nanoparticle targeting of MSCs in vascular injury. Biomaterials. 2013; 34(8):1987-1994. 
37. Ju S, Teng GJ, Lu H, et al. In vivo differentiation of magnetically labeled mesenchymal stem cells into hepatocytes for cell therapy to repair damaged liver. Invest Radiol. 2010;45(10):625-633.

38. Hughes S, El Haj AJ, Dobson J. Magnetic micro- and nanoparticle mediated activation of mechanosensitive ion channels. Med Eng Phys. 2005;27(9):754-762

39. Kirkham GR, Elliot KJ, Keramane A, et al. Hyperpolarization of human mesenchymal stem cells in response to magnetic force. IEEE Trans Nanobiosci. 2010;9(1):71-74.

40. Cartmell SH, Hughes S, Dobson J, El Haj A. Preliminary analysis of magnetic particle techniques for activating mechanotransduction in bone cells. In: Proceedings of the IEEE-EMBS Special Topic Conference on Molecular, Cellular and Tissue Engineering, 2002. New York, NY IEEE; 2002.
41. Lang SB. Pyroelectric effect in bone and tendon. Nature. 1966;212(5063): 704-705.

42. Huang DM, Hsiao JK, Chen YC, et al. The promotion of human mesenchymal stem cell proliferation by superparamagnetic iron oxide nanoparticles. Biomaterials. 2009;30(22):3645-3651.
International Journal of Nanomedicine

\section{Publish your work in this journal}

The International Journal of Nanomedicine is an international, peerreviewed journal focusing on the application of nanotechnology in diagnostics, therapeutics, and drug delivery systems throughout the biomedical field. This journal is indexed on PubMed Central, MedLine, CAS, SciSearch $®$, Current Contents $® /$ Clinical Medicine,

\section{Dovepress}

Journal Citation Reports/Science Edition, EMBase, Scopus and the Elsevier Bibliographic databases. The manuscript management system is completely online and includes a very quick and fair peer-review system, which is all easy to use. Visit http://www.dovepress.com/ testimonials.php to read real quotes from published authors.

Submit your manuscript here: http://www.dovepress.com/international-journal-of-nanomedicine-journal 